\title{
Shear capacity of steel-concrete composite beams with Hybrid Full Web and Truss System
}

\author{
Li Xiayuan ${ }^{1, a}$ Wan Shui ${ }^{1, b}$ Zhang Jiandong $^{1}$ Liu Wenjuan ${ }^{2}$ Zhang Fengping $^{2}$
}

${ }^{1}$ School of Transportation, Southeast University, Nanjing 210096, China ;

${ }^{2}$ Highway administration bureau of Zhengzhou city, Zhengzhou 450015, China ;

aEmail: lixiayuan123@163.com

${ }^{b}$ Corresponding author email: lanyu421@163.com

\section{Keywords: steel-concrete composite, HFWT system, Finite Element Method, ABAQUS}

Abstract. The paper is devoted to the behavior of steel-concrete beam with Hybrid Full Web and Truss system subjected to four-point loading mode. Steel-concrete composite beam with HFWT system was investigated both experimental and computational using finite element technic. In the finite element analysis, test specimens was modeled using finite element software ABAQUS and a non-linear analysis was performed. A large amount of Finite element models were built. The effects of the shear span ratio $\lambda$; the angle $\alpha$ between lateral truss plane and vertical plane in cross section; the angle $\beta$ between inclined truss and vertical plane in longitudinal plane were reported. A shear strength equation that considers the shear contribution of the concrete flange and the shear strength provided by the web of the steel beam and inclined truss system is proposed.

\section{Introduction}

Advantages of composite steel-concrete beams or girders in bridge and building structure are well recognized [1]. The I-section beams or H-piles are widely used in structural steel work; ordinary shapes of these beams are constructed from two parallel flanges and a web, as well as concrete flange. Over the past decades, a significant amount of experimental researcher on the behavior of composite steel-concrete beams has been carried out (Nie and Yuan in 1995; Nie and W in 1997; $\mathrm{Hu}$ and $\mathrm{N}$ in 1999; $\mathrm{Li}$ and $\mathrm{N}$ in 2002; $\mathrm{Hu}$ and $\mathrm{N}$ in 2004; etc.). Research efforts have also been directed toward the development of the establishment of design guidelines or design codes.

However, in construction application, the web usually bears most of the shear strength while the shear resistance of the concrete flange is neglected according to Chinese design code (GB 50017-2003[2]). In cases where the design of beams or girders is dominated by shear, which makes the web of the steel beam thicker essentially due to the only option, and it may result in a design that is not economical[3]. In 2004, 16 simplified supported composite beams specimens and 2 steel beams that are designed to investigated the shear resisting capacity by Nie in Tsinghua University [4], the formula of shear capacity of concrete flange is proposed, which has a good agreement with the test results. 
The idea of combining full web and truss elements in the steel-concrete composite bridges has been investigated in research and applications by Italy researcher Mauro E. Giuliani [5]. detailed in Fig.1. However, the further research is not reported.

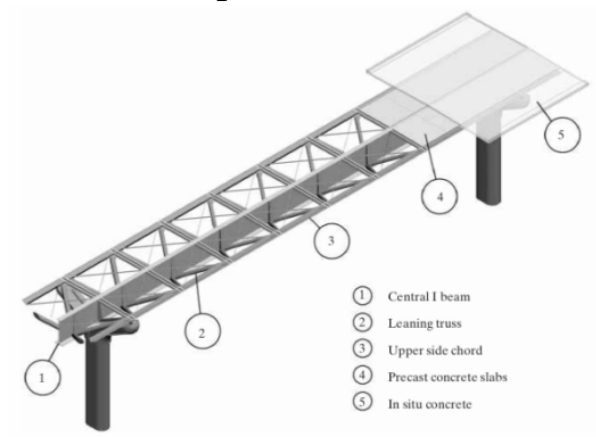

Fig. 1. Isometric view of structure

In recent years, the studies on the steel-concrete composite beam with Hybrid Full Web and Truss System were concentrated on the bending behavior. Shen [6] investigated the failure mechanism of theses beams under two symmetrical loads. Proper understanding of the shear resisting mechanism of steel-concrete composite is important, and they could yield a more efficient and rational design of composite beams.

This paper describes the investigation carried out on the shear behavior of steel-concrete composite beams with HFWT system. The aim of this study is to determine the effects of concrete slab, central I-shape beam and lateral trusses to the s composite beams' shear capacity. Calibrated finite element methods were adopted for these purposes. Steel beams and steel beams with HFWT system were also built to develop the benchmark results. The effects of the shear span ratio $\lambda$; the angle $\alpha$ between lateral truss plane and vertical plane in cross section; the angle $\beta$ between inclined truss and vertical plane in longitudinal plane were investigated.

\section{FEA model validations}

One model of beam was selected for the experimental test and FEA model validation, which is designated as: HFWT-test. The detail dimensions of test specimen are given in Table 1 and illustrated in Fig.2. The two parallel flanges were made from flat bar of $150 \mathrm{~mm}$ wide and $8 \mathrm{~mm}$ thick, the web was made from flat bar of $300 \mathrm{~mm}$ deep and $8 \mathrm{~mm}$ thick; the pipe of an outer diameter of $40 \mathrm{~mm}$ and $3 \mathrm{~mm}$ thickness was used to produce upper chord; while the pipe of an outer diameter of $32 \mathrm{~mm}$ and $3 \mathrm{~mm}$ thickness was used to produce web member. The beam tested was $3000 \mathrm{~mm}$ in length.

In addition, coupons were also collected from the ordinary I-section beam, upper chord, web member. The size of the tensile specimens fabricated was referred to the standard test methods and definitions for mechanical testing of steel products from the Chinese National Standard of Metal Tensile Test Sample (GB6397-86).

Table 1 Test specimens' property

\begin{tabular}{ccccc}
\hline Type & Designation & $\begin{array}{c}\text { Yielding strength } \\
/ \mathrm{MPa}\end{array}$ & $\begin{array}{c}\text { Ultimate strength } \\
/ \mathrm{MPa}\end{array}$ & $\begin{array}{c}\text { Elastic modulus } \\
/ \mathrm{MPa}\end{array}$ \\
\hline I-section & $H 316 \times 150 \times 8 \times 8$ & 389 & 498 & $2.08 \times 10^{5}$ \\
\hline Upper chord & $\Phi 40 \times 3$ & 393 & 453 & $2.05 \times 10^{5}$ \\
\hline Web member & $\Phi 32 \times 3$ & 421 & 453 & $2.09 \times 10^{5}$ \\
\hline
\end{tabular}




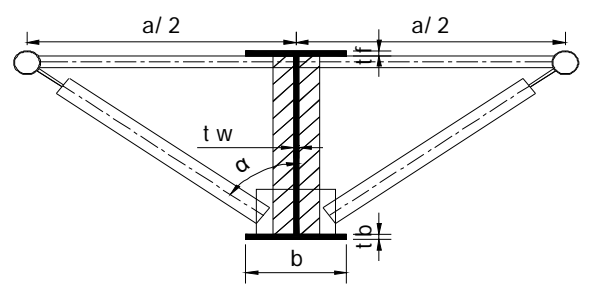

(a) plane

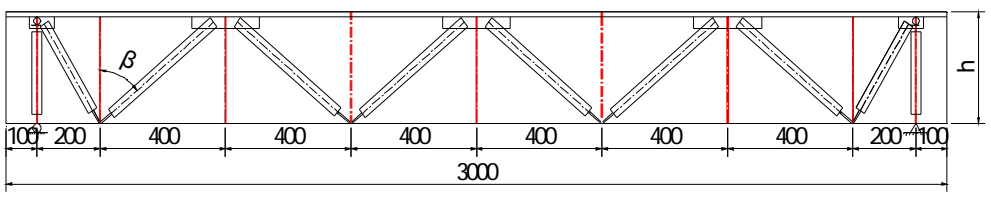

(b) Front view

Fig.2. geometry of the model test experimentally

A test rig was designed and commissioned as the base support for the test specimens and in providing the four-point bending condition as shown in Fig.3. Meanwhile a FEA model was built by ABAQUS based on the test specimen as shown in Fig.4. The shear force and mid-span deflection relationship for the tested specimen and FEA model are summarized in Fig.5.

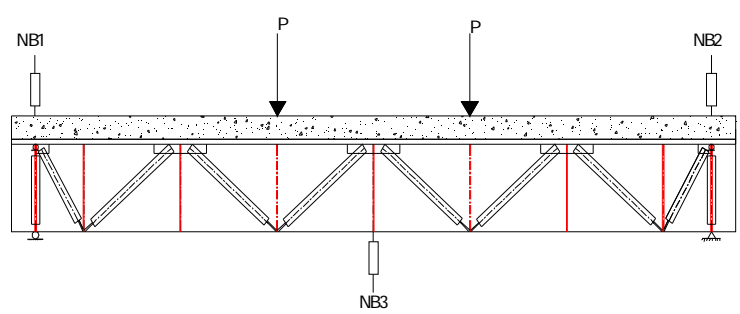

Fig.3. Experiment test rig

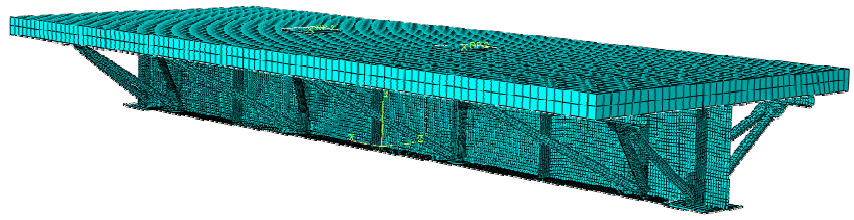

Fig.4. FEA model

The test results (Fig.5.) clearly indicate that FEA model agree well with experimental test. In the elastic stage, the two curves almost overlap, which means the experimental test simulated by ABAQUS software is correct; thought the two curves have a little deviation in the elastoplastic stage; the estimation error range can be controlled within 6 percent. In a word, by using Finite Element Analysis, we can simulate the real performance of steel-concrete composite bridges with HFWT system.

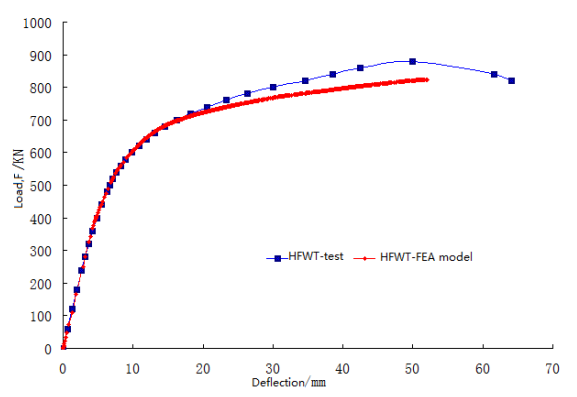

Fig.5. $F-\delta$ curves (HFWT-test and HFWT-FEA model)

\section{Numerical Finite Element Model}

The analyzed numerical models are developed in ABAQUS finite element environment. The model is based on solid model and shell model using 8 nodes (C3D8R) and 4 nodes (S4R) respectively. In this paper, three types of model are considered, steel I-shape beam (SI in short, shown in Fig.6. (a)), steel beam with HFWT system ( $\mathrm{SH}$ in short, shown in Fig.6. (b)), steel-concrete composite beam with HFWT system (SCH in short shown in Fig.6. (c)). the effects of 
the shear span ratio $\lambda$; the angle $\alpha$ between lateral truss plane and vertical plane in cross section; the angle $\beta$ between inclined truss and vertical plane in longitudinal plane were considered in modeling. The truss shear capacity could be obtained by comparing SI and SH, for SI were built to as bench mark results for SH. The concrete slab shear capacity could be obtained by comparing $\mathrm{SH}$ and $\mathrm{SCH}$, for $\mathrm{SH}$ were built to as bench mark results for $\mathrm{SCH}$.

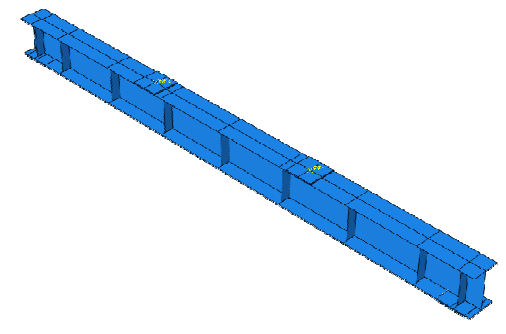

(a) I-shape beam

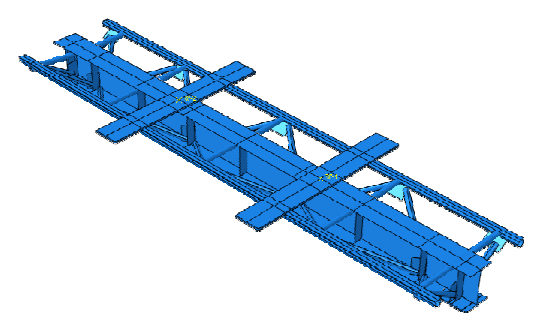

(b) Steel-HFWT beam

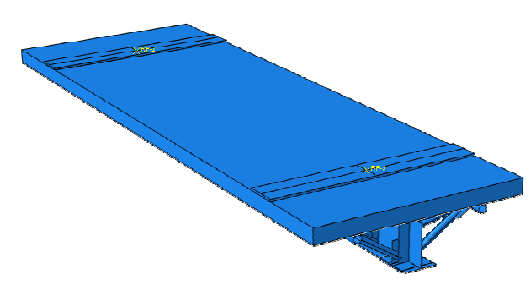

(c) Steel-Concrete HFWT beam

Fig.6. Three type of FEA model

The total strength of the composite beam is suggested to adopt the following widely used additive equation:

$$
\begin{aligned}
& V_{u}=V_{u s}+V_{u t}+V_{u c} \\
& \text { For, } V_{u s}=\frac{f_{y d}}{\sqrt{3}} A_{v}, \mathrm{~V}_{\mathrm{ut}}=5 F_{y w} A_{T} \cos \alpha e^{-0.7 \lambda_{s}} V_{u c}=\left(-0.56 \ln \left(\lambda_{c}\right)+1.5\right) \sqrt{f_{c}{ }^{\prime}} b_{f} h_{f}
\end{aligned}
$$

\section{Conclusions}

In this investigation, the shear capacity of structural beam with HFWT system has been studied both experimental and computational. A non-linear finite element software (ABAQUS) was used for these purpose, comparisons of results were also made between them to evaluate the accuracy of the developed finite element model. The results showed that using finite element method to carry out the numerical simulation by software in reality in order to get the condition of mid-span deflection and force is well. A large amount of Finite element models were built. The effects of the shear span ratio $\lambda$; the angle $\alpha$ between lateral truss plane and vertical plane in cross section; the angle $\beta$ between inclined truss and vertical plane in longitudinal plane were reported.

An empirical equation based on the finite element model results was suggested for calculating the shear strength provided by the concrete, the central I-shape steel and inclined truss system as well. It was also suggested that the total shear strength of composite beam with HFWT system can be given by an additive formula of the concrete flange contribution and the shear strength provided by the web of the steel beam and inclined truss system.

\section{Acknowledgements}

This work was financially supported by was funded by the National Natural Science Foundation of China under Grant No.51478107 (Shear Deformation and Shear Buckling of Non-Uniform Composite Girder Bridges with Corrugated Steel Webs,). 


\section{References}

[1] J. G. Nie, M. X. Tao, etc. Advances of research on steel-concrete composite bridges [J]. China Civil Engineering Journal. 2012,45(6),110 122

[2] GB50017-2003, Code for Design of Steel Structure [S].2003

[3] J. G. Nie, L. C, Y, X. Composite shear behavior of steel-concrete composite beams under sagging moment [J]. J Tsinghua University (Sci \& Tech), 2202,42(6),835 838

[4] J. G, Nie. Y. X, C. L. Experimental studies on shear strength of steel-concrete composite beams [J]. Journal of Structural Engineering. 2004, 130(8), 1206 1213

[5] Mauro E Giuliani. Hybrid Truss and Full Web System for New Sardinia Viaducts [J]. Structural Engineering International, 2003,(2):119 123

[6] J. Shen, J.B. Chen, X. Y. Li. Experimental study on the bearing capacity of steel-concrete composite beams based on the HFWT system [J]. Journal of Changzhou Institute of Technology. 2014,27(2),7 11 